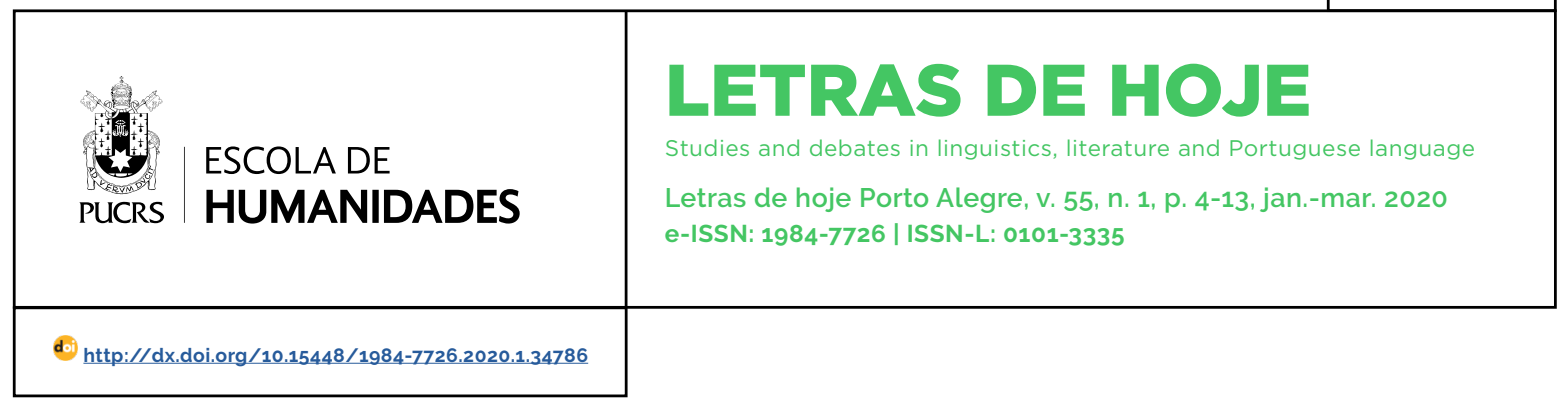

\title{
Tecnologia e literatura: as narrativas transmediáticas
}

\author{
Technology and literature: the transmedia storytelling \\ Tecnologia y literatura: las narrativas transmedia
}

\section{Moisés de Lemos \\ Martins $^{1}$}

orcid.org/0000-0003-3072-2904

moiseslmartins@gmail.com

Recebido em: 12 jul 2019.

Aprovado em: 13 nov. 2019

Publicado em: 14 abr. 2020.
Resumo: Foi o regime literário que produziu o Ocidente. No nosso tempo, todavia, o regime literário perdeu centralidade. Hoje, a cultura tem uma predominância tecnológica, sendo através deste processo de mediação que se exprime, cada vez mais, a vida contemporânea. Com efeito, os novos territórios, paisagens, atmosferas e ambientes tecnológicos levaram as comunidades humanas a circum-navegar sites, portais, blogues, videojogos, aplicações, repositórios digitais, museus virtuais, e também realidades virtuais implantadas em ambientes imersivos. Um tal processo teve como consequência a multiplicação dos conteúdos e a convergência de formatos, plataformas informáticas e linguagens. $O$ movimento de aparelhamento tecnológico da cultura expandiu a experiência humana. Podemos falar, nestas circunstâncias, de uma galáxia de novos fluxos, ressonâncias, ritmos, cadências, sonoridades, durações, vibrações, que permitem a abertura das comunidades humanas à configuração de novas possibilidades de futuro. Entretanto, a expansão da experiência humana abriu também a possibilidade de novas narrativas sobre o humano. A essas narrativas damos-lhe 0 nome de narrativas transmediáticas, por se apoiarem na convergência dos média digitais. Este estudo interroga as narrativas transmediáticas, que se desdobram através de múltiplas plataformas. Procuramos saber em que medida estas narrativas constituem uma escrita criativa e literária, uma escrita que não responda apenas a necessidades de gestão e de comunicação política, nem se esgote na repetição, adaptação e propagação da mesma história.

Palavras-chave: Narrativas transmediáticas. Média digitais. Tecnologia e literatura. Cultura tecnológica. Circum-navegação tecnológica.

Abstract: The West was produced by the literary regime. In our times, however, the literary regime has lost centrality. These days, culture has a technological predominance, and through this process of mediation, contemporary life is increasingly expressed. In fact, the new territories, landscapes, atmospheres and technological environments led human communities to circumnavigate sites, portals, blogs, videogames, applications, digital repositories, virtual museums, and also virtual realities deployed in immersive environments. This process has resulted in the multiplication of contents and convergence of formats, computer platforms and languages. The movement of culture technological apparatus has expanded the human experience. We can talk in these circumstances, of a galaxy of new flows, resonances, rhythms, cadences, sounds, durations, vibrations, which allow human communities to be open to setting new future possibilities. The expansion of human experience has also opened the possibility of new narratives about the human. These narratives are called transmedia storytelling, because they rely on digital media convergence. This study examines transmedia storytelling, which unfold across multiple platforms. Let's try to understand how these narratives constitute a creative and literary writing, that means, a writing that does not just respond to management and political communication needs nor runs out in repetition, adaptation and propagation of the same story.

Keywords: Transmedia storytelling. Digital media. Technology and literature. Technological culture. Technological circumnavigation.

Resumen: Occidente fue producido por el régimen literario. En nuestro tiempo, sin embargo, el régimen literario ha perdido su centralidad. Hoy, la cultura 
tiene un predominio tecnológico, y es a través de este proceso de mediación que la vida contemporánea se expresa cada vez más. De hecho, los nuevos territorios, paisajes, atmósferas y entornos tecnológicos han llevado a las comunidades humanas a circunnavegar sitios web, portales, blogs, videojuegos, aplicaciones, repositorios digitales, museos virtuales, asi como realidades virtuales implantadas en entornos inmersivos. Tal proceso dio como resultado la multiplicación de contenidos y la convergencia de formatos, plataformas informáticas y lenguajes.

El movimiento de organización tecnológica de la cultura expandió la experiencia humana. Podemos hablar, en estas circunstancias, de una galaxia de nuevos flujos, resonancias, ritmos, cadencias, sonidos, duraciones, vibraciones, que permiten la apertura de las comunidades humanas a la configuración de nuevas posibilidades para el futuro. La expansión de la experiencia humana también abrió la posibilidad de nuevas narrativas sobre lo humano. A estas narrativas las llamamos narrativas transmedia porque se basan en la convergencia de los medios digitales. Este estudio cuestiona narrativas transmedia, que se desarrollan en múltiples plataformas. Pretendemos saber en qué medida estas narrativas constituyen una escritura creativa y literaria, una escritura que no solo responda a las necesidades de gestión y comunicación política, ni se quede sin repetición, adaptación y propagación de la misma historia.

Palabras clave: Narrativas transmedia. Medios digitales. Tecnología y literatura. Cultura tecnológica. Circunnavegación tecnológica.

\section{Um movimento de translação na cultura das estrelas para os ecrãs}

Foi o regime da palavra que fez o Ocidente - a democracia e as suas instituições como promessa de liberdade, as universidades como promessa de emancipação, o jornalismo como promessa de cidadania. Um tal regime tem uma natureza argumentativa - utiliza meios para atingir fins. Foi por essa razão que Aristóteles (1965) o caraterizou como teleológico, por se fundar em ações que têm uma finalidade 2 . E a tradição judaico-cristã acrescentou-lhe uma dimensão escatológica, estabelecendo que essa finalidade é libertadora, dado que nos redime (Lyotard, 1993, p. 90).

O regime da palavra procede por pensamentos ou ideias, que servem valores universais: o bem, o bom, o justo, o verdadeiro. Tem como instrumentos de conhecimento conceitos e raciocinios, que visam um efeito persuasivo. Funda uma idade literária em que os grandes conceitos convocam um grande estilo. É assim com as grandes obras, sejam literárias, sejam artísticas. A criatividade é nelas ideia, ensaio sobre o humano, é invenção de linguagem e de pensamento, e é também e acima de tudo, autoria, estilo, expressividade, ficção, criação, invenção.

O regime da palavra remete para o regime da analogia, com todas as coisas a serem explicadas por uma causa anterior, sendo que a primeira das causas é Deus, ou então, fundamento, essência, substância, transcendência, existência, o próprio homem e a consciência. O regime da palavra abriu, pois, uma idade da promessa, que nos inscreveu numa história da salvação, entre uma génese e um apocalipse, o que nos garantiu um fundamento seguro, um território conhecido e uma identidade estável.

Como instituição literária, que integra o regime da palavra, os média constituem uma promessa de cidadania e exercem uma pedagogia cívica ao serviço da democracia. O imaginário social do regime da palavra projeta um pathos dramático, que é animado por uma sintese redentora e comandado pelo logos, que além de palavra é também razão, sentido e direção. Nesse regime são valorizadas as formas clássicas, de linhas retas e superficies transparentes. E o ethos encaminha para o sublime, propondo valores elevados e impondo um movimento de baixo para cima. A viagem humana assemelha-se, então, a uma passagem, porque se trata de uma viagem controlada, sem perigos inesperados que possa recear ${ }^{3}$.

Passado, todavia, mais de um século sobre o premonitório texto futurista de Marinetti (1909), que vê a "beleza da velocidade" como "um novo assombro" da época e o carro de corrida, que é uma figuração tecnológica, como a sua exata

\footnotetext{
2 "A arte e a investigação, assim como toda a ação e toda a deliberação, tendem, ao que parece, para um bem. Temos, pois, razão em definir o bem desta maneira: aquilo para que tendemos em todas as circunstâncias" (Aristóteles, 1965, Livro 1, capítulo, 1. ${ }^{\circ}$, p. 19).

3 Analisei o imaginário do regime da palavra, um imaginário dramático, governado pelo logos, que se exprime por formas clássicas e sublimes, ao confrontá-lo, em vários estudos, com o imaginário da era tecnológica, um regime trágico, governado pelo pathos, que se exprime por formas barrocas e grotescas (MARTINS, 2002a, 2002b, 2002c, 2011a). Mas fi-lo, em pormenor e mais apuradamente, quando tomei a moda como caso de estudo (MARTINS, 2011b, 2013, 2015a, 2016).
} 
configuração4, e caminhando nós a passos largos para o centenário do profético texto de Jünger (1930) sobre a "mobilização total" do humano, que Sloterdijk (2000) entende ser uma "mobilização infinita", podemos dizer que se acentuou na cultura a translação, da palavra para o número, o que quer dizer, da palavra para a imagem de produção tecnológica (MARTINS, 2011a) ${ }^{5}$

Nesse novo regime, que nos mobiliza tecnologicamente para o presente, para as urgências do quotidiano (MARTINS, 2010), que são sempre as urgências de uma competição qualquer, para um mercado qualquer, dá-se a retração do logos e a promoção do pathos, a retração da razão e a promoção da emoção, com a substituição do horizonte de comunidade pelos mais variados interesses, próprios de uma sociedade tribal ${ }^{6}$.

E a época deixou de ser de promessa. Por um lado, como assinala Jorge Luís Borges, no poema "Unending gift", "apenas pela palavra podemos prometer" (BORGES, 1998). Por outro lado, mobilizada para o presente, a época passou a ser de "meios sem fins" (AGAMBEN, 1995). A criatividade é agora a expressividade humana apoiada no computador. Ser expressivo, hoje, é frequentar os novos territórios, as novas paisagens e os novos ambientes das narrativas transmediáticas, que Jenkins (2003) denominou de "transmedia storytelling", assim como apoiar-se nos novos conhecimentos tecnológicos da inovação, hibridez, multimodalidade e interatividade que eles supõem (MARTINS, 2012). O imaginário social projeta um pathos trágico, com a condição humana a não ser redimida por nenhuma superação das contradições. Sem nada que nela constitua um fundamento seguro, tendo pela frente um território desconhecido e uma identidade incerta, a atual situação não pode deixar de ser de grande perigo. No atual regime tecnológico, o logos valoriza as formas barrocas, de linhas curvas e superficies côncavas, rugosas e irregulares, habitadas por sombras, que abrem para mundos interiores. $E$ o ethos é grotesco, dando-se uma inversão de valores, num movimento de cima para baixo ${ }^{7}$. A viagem humana assemelha-se, assim, a uma intérmina travessia (Martins, 2011a) ${ }^{8}$.

Neste novo regime, os média, que já não são sobretudo impressos, ou analógicos, tendo passado a média digitais, exprimem e aprofundam, cada vez mais, a passagem de uma utopia de comunidade a uma comunidade sem utopia, inscrevendo-nos numa crise permanente (MARTINS, 2002b; 2003; 2008).

Deixámos, é um facto, de olhar para as estrelas e passámos a olhar para os ecrãs, como assinala Paul Virilio (2001, p. 135). Ou seja, da história de sentido em que se inscreviam as estrelas, o Ocidente abriu caminho para os ecrãs, o que quer dizer, para "a inovação, a hibridez e a interatividade" (MARTINS, 2012, p. 49).

Ao ter-se dado, no nosso tempo, a translação do regime da palavra para o regime do número, o humano entrou "em sofrimento de finalidade" (LYOTARD, 1993, p. 93; MARTINS, 2002C). Ou seja, uma vez expulso do regime da palavra e sendo mobilizado tecnologicamente para o mercado (MARTINS, 2010; MARTINS apud CARVALHO, 2019), o humano fica marcado pela instabilidade e o desassossego, passando a ser identificado, cada vez mais, pelo seu caráter instável, sinuoso, viscoso, titubeante, labiríntico e enigmático.

O abandono do regime da palavra e a sua substituição pelo regime do número concretiza a atual cinética de um mundo marcado pela

\footnotetext{
4 "Nós afirmamos que a magnificência do mundo se enriqueceu com um novo assombro: a beleza da velocidade. Um automóvel de corrida cujo motor é embelezado com tubos grossos, semelhantes a serpentes de hálito explosivo... um automóvel rugidor, que parece correr sobre a metralha, é mais bonito que a Vitória de Samotrácia" (MARINETTI, 1973,1909).

5 Sobre o movimento de translação, por onde tem passado a nossa civilização, da palavra para o número, a imagem, a emoção e o múltiplo, ver: MARTINS, 2011a, 2011b.

6 Michel Maffesoli associa a eclosão do tribalismo na sociedade atual ao "declínio do individualismo". É isso que propõe em Le temps des tribus, obra que publicou em 1988. Neste aspeto distancio-me da sua posição, porque o espírito de tribo é emocional, e não racional, é de multidão, e não de comunidade. Na tribo não existem exigências de cidadania, que são uma promessa de comunidade, mas unicamente as exigências de uma "ética da estética", uma ética da emoção, próprias da "efervescência" pós-moderna (MAFFESOLI, 1990).

Sobre o imaginário melancólico da época tecnológica, um imaginário trágico, barroco e grotesco, consultar a nota 3. Especificamente sobre o grotesco, ver Bakhtin (1970) e Sodré e Paiva (2002). Sobre o barroco, consultar Wölfflin (1991); d'Ors (1968/1936); Rousset (1953).

8 A ideia de travessia, associada a uma viagem perigosa, dado que não controlada (enigmática, labirintica e arriscada), tomo-a de João Guimarães Rosa, no romance O Grande Sertão: Veredas, publicado em 1967.
} 
insegurança, pelo desconhecido e pela instabilidade (MARTINS, 2007b; 2015a).

A nossa situação é, hoje, de desconforto e malestar: os passos por onde vamos a caminho deixaram de poder apoiar-se em "rocha, cabo ou cais", para falarmos como Sophia de Mello Breyner (2014), no poema "Procelária", sendo antes passos incertos, ambivalentes e desassossegados, no permanente movimento de uma viagem de travessia sem fim.

\section{A mediação tecnológica e a expansão da experiência humana ${ }^{9}$}

As narrativas contemporâneas falam-nos da atual experiência do humano, dando-nos a ver paisagens tecnológicas, que exprimem atmosferas sensiveis e sociais, as quais tanto remetem para um tempo de mobilização total para o mercado (MARTINS, 2010; MARTINS apud CARVALHO, 2019), como simultaneamente remetem para um tempo agitado, um tempo de sobreaquecimento contínuo, que mobiliza as emoções e configura um imaginário social de formas melancólicas. Tais formas resultam da combinação entre techne e aesthesis, ou seja, entre técnica e emoção, e também, entre techne e arche, o que quer dizer, entre o novo e o arcaico (MARTINS, 2003, 2005, 2007a, 2007b, 2011d).

Estando todos nós convocados a fazer esta viagem tecnológica, como quem abre "a última porta para noite" da cultura (STEINER, 1992, p. 6) ${ }^{10}$, relembro a conferência de Heidegger (1988, p. 38), pronunciada em 1953, sobre "A questão da técnica" ("Die Frage nach der Technik"). Embora o filósofo alemão considerasse a técnica como o perigo, argumentou com o verso de Hölderlin, mas "Lá onde está o perigo cresce também o que salva".

Constituindo a fusão de techne e bios o acontecimento maior da experiência contemporânea, assim como o seu mais exigente desafio, não podemos deixar de lhe responder. $\mathrm{E}$ essa resposta coloca-nos perante a necessidade de empreender uma viagem, que já noutros estudos caraterizei como uma circum-navegação tecnológica ${ }^{11}$, atravessando territórios, atmosferas e paisagens construidas pela hibridez de techne e bios, além da amálgama, já assinalada, de techne e aesthesis, e techne e arche (MARTINS, 2011a; MARTINS; OLIVEIRA; CORREIA, 2011)12.

O movimento de aparelhamento tecnológico da cultura expandiu a experiência humana. E ao expandi-la, abriu caminho a outras narrativas sobre o humano - as narrativas transmediáticas. Os novos territórios, paisagens, atmosferas e ambientes tecnológicos, tais como narrativas transmediáticas, sites, portais, blogues, videojogos, aplicações, repositórios digitais, museus virtuais, e ainda a instalação de realidades virtuais em ambientes imersivos, multiplicaram os conteúdos e fizeram convergir formatos, plataformas informáticas e linguagens. Uns e outros estão na origem de uma expansão da "imaginação simbólica", para utilizarmos uma antiga formulação a que Gilbert Durand (1964) recorreu, embora noutro contexto, dando forma a novas possibilidades de comunidade, as comunidades virtuais.

Com efeito, a atual cinética do mundo conta hoje com a utilização de uma mediação tecnológica nos processos coletivos de

\footnotetext{
9 Alguns parágrafos, neste ponto e também no seguinte, constituem a reescrita de um ou outro andamento de estudo anterior, publicado com o título: "Os países lusófonos e o desafio de uma circum-navegação tecnológica" (MARTINS, 2018).

10 Querendo precisar o sentido da viagem que quer empreender connosco no ensaio No Castelo do Barba Azul. Algumas notas para uma redefinição da cultura. Steiner escreve logo no frontispício da obra: "Dir-se-ia que estamos, no que se refere a uma teoria da cultura, no mesmo ponto em que a Judite de Bartok, quando pede para abrir a última porta para a noite" (STEINER, 1992/1971, p. 6). Steiner convoca a personagem Judite, do libreto de uma das óperas de Bartok, que tomara como modelo o conto tradicional, No Castelo do Barba Azul. E o seu ensaio sobre a cultura contemporânea, uma cultura de matriz tecnológica, é uma porta aberta sobre "O grande tédio" (título do primeiro capítulo); sobre "Uma temporada no Inferno" (título do segundo capítulo), sobre a "Pós-cultura" (título do terceiro capítulo"). 11 Tenho utilizado a figura da circum-navegação tecnológica em muitos estudos, designadamente nos seguintes: Maffesoli e Martins, 2011, "Ciberculturas"; Martins, 2011a, Crise no castelo da cultura. Das estrelas para as telas; Martins, 2011/12, "Média digitais - hibridez, interatividade, multimodalidade"; Martins, 2015b, "Média digitais e lusofonia"; Martins, M. L., 2017, "Comunicação da ciência, acesso aberto do conhecimento e repositórios digitais. O futuro das comunidades lusófonas e ibero-americanas de Ciências Sociais e Humanas"; Martins M. L., 2018, "Os países lusófonos e o desafio de uma circum-navegação tecnológica".

12 A figura da circum-navegação, associada à ideia de viagem tecnológica, é desenvolvida, originalmente, na tese de doutoramento de Stéphane Hugon, defendida em 2007, na Sorbonne, com o titulo, Circumnavigations, la construction sociale de l'identité en ligne. Esta tese foi publicada em 2010, mantendo a figura da circum-navegação no título: Circumnavigations. L'Imaginaire du voyage dans l'expérience Internet. Colocando-se do ponto de vista de "uma sociologia dos espaços eletrónicos", Hugon interroga, entre outros aspetos, "uma cultura da deambulação", "uma genealogia da deriva", "o que significa habitar", "o que é uma paisagem" e, ainda, "a dinâmica comunitária".
} 
configuração e construção identitárias, e também de tecelagem e produção de memórias sociais (MARTINS, 2012; 2015b). É através desse processo de mediação que se exprime, cada vez mais, a vida contemporânea, por natureza multicultural, intercultural e transcultural. Podemos falar, nessas circunstâncias, de uma galáxia de fluxos, ressonâncias, ritmos, cadências, sonoridades, durações, vibrações, que impedem as comunidades humanas de se fixarem em coisa definida, ou seja, definitiva, para se abrirem ao desenho de transfigurações "mitopoéticas", com novas possibilidades de futuro (DERRIDA, 1967, p. 418-419).

Mantendo como ângulo de enfoque o atual contexto tecnológico, gostaria de relembrar Thomas Kuhn. Ao refletir sobre as descobertas cientificas e tecnológicas, Kuhn (1962) pôde mostrar-nos de que modo tais descobertas constituiram a causa e o efeito daquilo a que chamamos paradigma. Em sentido estrito, podemos compreender o paradigma como uma matriz, que permite a eclosão de uma vida nova. E a vida nova que se encontra nos dias de hoje em gestação no Ocidente é exatamente aquilo a que chamamos de comunidades virtuais. Neste paradigma tornase visivel a hibridez do tempo, onde a energia das máquinas e as emoções dos homens se misturam como numa amálgama. E o ciberespaço, enquanto ambiente de produção informática, tanto constitui a viagem que esperamos fazer, como o oceano em que importa navegar.

Com efeito, a nova circum-navegação tecnológica concretiza o novo paradigma cibercultural, uma travessia em direção à Nova América de um novo arquivo cultural, que reativa em nós formas antigas, o arcaísmo, enfim a mitologia, e ao mesmo tempo reconfigura em permanência a comunidade, pelo desejo de ser-e-estar-com-outros.

\section{Dos média digitais à criação literária}

As narrativas transmediáticas, a que Jenkins (2003) chama "transmedia storytelling", aparecem por meados dos anos 1960, nos Estados Unidos, como uma nova "a arte de contar histórias". Essa nova arte consiste em contar uma história através de múltiplos artefactos, em diversos média, os quais, sendo autónomos, ao mesmo tempo se complementam para formar uma história maior (SOUSA; ZAGALO; MARTINS, 2012). As narrativas transmediáticas realizam, pois, um tipo de narração que "se desdobra através de múltiplas plataformas mediáticas, dando cada novo texto uma contribuição distintiva e valiosa para o todo" (JENKINS, 2006, p. 95-96). Carlos Alberto Scolari, entretanto, precisa que se trata de "uma estrutura narrativa particular que se expande, tanto através de diferentes linguagens (verbal, icónica, etc.), como de média (cinema, desenhos animados, televisão, videojogos, etc.)" (SCOLARI, 2009, p. 587). Cada meio apresenta a parte da história que melhor se adequa ao seu tipo de representação semiótica, no sentido de a completar (JENKINS, 2006, p. 96)

No entanto, as narrativas transmediáticas têm sido declinadas, por toda a parte, através de modalidades cada vez mais sofisticadas, nos mundos da gestão e da comunicação política, mobilizando utilizações da narrativa muito diferentes, que vão da narrativa oral, tal como a praticam os tradicionais contadores de histórias, até às "digital storytelling", que praticam a imersão virtual em universos multissensoriais e fortemente encenados (SALMAN, 2007, p. 7).

$O$ facto de as narrativas transmediáticas estarem muito ligadas ao mundo da gestão e da comunicação política levou Christian Salman a classificar a "storytelling" como "uma máquina de fabricar histórias e de formatar espíritos" (SALMAN, 2007) ${ }^{13}$.

Também Janet Wasco reconhece que as narrativas transmediáticas são produtos que "promovem a sociedade de consumo", dado o seu caráter comercial e lúdico (WASCO, 1994, p. 187). Em Hollywood in the Information Age, Wasco (1994, p. 4) assinala a crescente tendência de Hollywood, na "era da informação",

13 É exatamente este o título da obra de Salmon (2007): Storytelling. La Machine à fabriquer des histories et à formater les esprits. 
para levar os filmes "para fora do grande ecrã", socorrendo-se de brinquedos, jogos, bandas sonoras, merchandising, atividades de marketing, livros de colorir, parques temáticos, cereais, em campanhas que são cada vez mais "deliberadas e cuidadosamente coordenadas". E até as formas de promoção dos filmes incluem a transposição de personagens ou da história para programas de televisão, a criação de spin-offs narrativas, videojogos, revistas ou "livros como-o-filme-foifeito, etc." (WASCO, 1994, p. 187).

Não se pense, no entanto, que as narrativas transmediáticas se cingem à produção de artefactos, comerciais ou lúdicos, para consumo. Também se trata da criação de novas histórias (WASCO, 1994, p. 4). Na atual condição tecnológica da narrativa, os mundos fictícios propagamse por múltiplos média e formatos de imagem em movimento. Vendo neles também uma expansão da narrativa, Janet Wasco considera como histórias novas esses novos mundos ficcionais (WASCO,1994, p. 4). E o que é facto é que, se olharmos, por exemplo, para sagas como Star Wars ou Star Trek, verificamos que a sua natureza hibrida combina adaptações, com produtos comerciais e expansões da história. Por essa razão, aliás, as narrativas transmediáticas, que significam a expansão da narrativa, por meio de vários média (SOUSA; MARTINS; ZAGALO, 2016) colocam-nos um desafio de leitura bem distinto daquele que é assinalado por Roman Jakobson, em Lingüistica e Comunicação (2003), que supõe uma tradução intersemiótica, ou uma transmutação de sentido, no processo de interpretação dos signos verbais por meio de sistemas de signos não verbais (MARTINS, 2018).

A expressão "transmedia storytelling" foi cunhada por Jenkins (2003). François Jost prefere falar de "luta intermidia" (JOST, 2011, p. 95), em vez de utilizar a expressão de Jenkins (2006) de "convergência" dos média. Carlos Alberto Scolari utiliza como sinónimos os conceitos de "transmedia storytelling" e "crossmedia", o último dos quais, reconhece, é mais usado nos meios profissionais do que nos meios académicos (SCOLARI, 2011, p. 128). Assinalando que o "transmedia storytelling" começa, de forma difusa, em diferentes média, como a literatura, o cinema, a televisão, os videojogos, os desenhos animados, e até bonecos (SCOLARI, 2013, p. 138), Carlos Alberto Scolari conclui, em sintese, que a narrativa transmediática nomeia uma experiência, ou seja "uma prática de produção de sentido e uma prática interpretativa, baseadas em histórias que se concretizam através da combinação de linguagens, meios e plataformas" (SCOLARI, 2013, p. 25).

No novo sistema cultural, de natureza tecnológica, os livros, filmes e séries de televisão se mantêm. Mas têm agora que conviver com blogues, vídeos no YouTube e páginas na Wikipedia. E a sua própria natureza foi alterada, ao serem transferidos para formatos digitais e ao ser-lhes impostas diferentes formas de consumo, que convocam DVD, iPads e smarphones.

As narrativas transmediáticas expandem a nossa experiência do mundo com conteúdos digitais. E, ao fazê-lo, expandem, também, a nossa capacidade para produzir histórias novas, através de um processo que não é apenas de imitação e de propagação, mas igualmente de criação. Esse processo imita, reproduz, reconta, remedeia, adapta, estende e reinventa, indefinidamente, as histórias conhecidas. Mas, além disso, permite ficcionar novas histórias, com a instalação de realidades virtuais em ambientes imersivos, como os videojogos e as narrativas interativas na rede, no cinema, na televisão, em DVD.

Tomando de assalto a cultura popular, as tecnologias digitais e criativas, multimodais, hibridas, inovadoras e interativas, que convocam para a mesma "galáxia semântica" (expressão de Scolari), a indústria, a arte, a academia e as populações, permitem-nos, hoje, uma navegação universal, por novos territórios, novos ambientes, novas paisagens e novas atmosferas.

Esta circum-navegação tecnológica, que se apoia no computador e faz convergir no mesmo ecrã, a máquina fotográfica, a máquina de filmar, a programação informática e o design gráfico, não deixa, todavia, de constituir uma travessia. Porque muitas das práticas transmediáticas, enquanto práticas de imitação e propagação não passam de 
artificios de marketing, ao serviço da competição, que concretiza a ideologia do mercado. Além disso, as práticas assentes na repetição, por exemplo as sequelas de videojogos, não são verdadeiramente criativas, pelo que têm diminuto valor artístico. E é ainda de uma travessia que se trata a permanência nas narrativas transmediáticas da tendência para a gamificação, que se verifica não apenas nos conteúdos, mas também na inclusão de "experiências lúdico-imersivas", como acontece com os jogos de realidade alternativa (SCOLARI, 2013, p. 297).

É verdade, com a abertura dos territórios, ambientes, paisagens e atmosferas da nova cultura tecnológica, nunca nas narrativas foram tão poderosos o "simulacro e a simulação", para convocarmos o título de uma das obras de Baudrillard (1981). Mas é também por essa mesma razão que vemos a comunidade humana sucumbir tão rotundamente ao fascínio emocional, ao espetáculo extático e à alienação do consumo.

As narrativas transmediáticas constituem, pois, uma travessia apoiada na "imaginação simbólica", nos termos em que a entende Gilbert Durand (1964; 1960; 1979). Mas a travessia que importa fazer não dispensa, também, o logos argumentativo, que se concretiza no recurso às literacias digitais. São, com efeito, estas literacias que expandem a nossa capacidade de narrar, ao tornarem possiveis a pesquisa de informação online, a interpretação e a avaliação de conteúdos digitais, e mesmo a sua produção.

Porque os médias digitais são inovações tecnológicas, as literacias digitais obrigam-nos a discutir, antes de mais nada, a programação e o design (FOSTER, 2002), os quais generalizam o processo de produção de imagens como práticas de "simulacro e simulação" (BAUDRILLARD, 1981), entre a troca lúdica e a partilha diária de imagens digitais, nos ambientes reais e virtuais dos nossos smartphones e computadores ${ }^{14}$. Porque os média digitais significam também a hibridez, as literacias digitais abrem espaço para seres artificiais, mundos virtuais e experiências simulacrais.
Porque os média digitais significam ainda a multimodalidade, as literacias digitais implicam novas práticas da linguagem e da comunicação, ou seja, novas práticas de produção do sentido, assim como novas profissões: web designers, curadores online, gestores de museus virtuais, ativistas da web, youtubers, influencers... E porque os média digitais significam a interatividade, as literacias digitais levam-nos a interrogar a relação entre o homem e o computador. Esta relação supõe a liberdade e a autonomia dos atores sociais, e da mesma forma os seus constrangimentos específicos, uns decorrentes do uso de máquinas, e é o caso dos automatismos e repetições, outros da própria ação social, que se realiza sempre em condições concretas de tempo, espaço e interlocução ${ }^{15}$.

\section{Nota conclusiva}

Para concluir este estudo sobre o caráter criativo das narrativas transmediáticas e da sua ligação à literatura, relembro Marta Noronha e Sousa (2018). Ao relativizar as criticas da falta de criatividade, que possam ser endereçadas às narrativas transmediáticas, essta investigadora relembra que:

Romeo and Juliet é uma adaptação, à semelhança de muitas peças de Shakespeare e filmes de Hitchcock; a Odisseia, o segundo tomo de Don Quixote e The Lord of the Rings são sequelas; várias obras de Dickens têm personagens comuns, e na época são lançados os charutos Pickwick (nome de uma das personagens), assim como anúncios publicitários em táxis; Le Sphinx des Glaces, de Jules Verne, é uma continuação alógrafa de The Adventure of Arthur Gordon Pym, de Edgar Alan Poe; Ulysses, de Joyce, é uma transformação radical de uma obra venerada, e ninguém põe em causa a sua qualidade (SOUSA, 2018, p. 494-495).

Neste contexto, por muitas que sejam as dificuldades a enfrentar na travessia dos novos mares das narrativas transmediáticas, é legítimo pensar num horizonte de "democratização

14 Este processo de produção de imagens, que traduz uma prática geral de "simulacro e simulação", ocorre numa linha que é tanto de continuidade como de rotura com a máquina fotográfica, entre a troca lúdica e a partilha diária de imagens, de idêntica forma àquela que ocorreu, no passado, com os postais ilustrados (MARTINS; CORREIA, 2014).

15 Sobre "a linguagem dos novos média", ou dos média digitais, ver Lev Manovich (2001). 
da inovação e da criatividade", em que cada indivíduo possa expressar e comunicar o que a sua imaginação consiga criar (ZAGALO; BRANCO, 2012, p. 5). Ou seja, por muito que nos encontremos "num terreno semanticamente instável", segundo a expressão de Scolari (2009, p. 586; 2013, p. 13), estamos embarcados numa experiência de circum-navegação tecnológica. E nesta experiência atribuímo-nos uma "pele tecnológica" (KERCKHOVE, 1997), uma pele para a afeção, o que também quer dizer, uma pele para o ser-e-estar-com-outros. Circum-navegando os média digitais, tem sentido falarmos, pois, do caráter "mitopoético" dessa escrita, que consiste na criatividade em rede e na partilha da criação.

\section{Referências}

AGAMBEN, G. Moyens sans fin. Notes sur la politique. Paris: Payot \& Rivages, 1995

ANDRESEN, Sophia de Mello Breyner. Procelária. In: ANDRESEN, Sophia de Mello Breyner. Geografia. Lisboa: Assirio \& Alvim, 2014. p. 35-43. https://doi. org/10.11606/d.8.2006.tde-24082007-152926

ARISTÓTELES. Éthique de Nicomaque. Tradução, Prefácio e Notas de Jean Voilquin. Paris: Garnier Flammarion, 1965

BAKHTIN, M. L'oeuvre de François Rabelais et la culture populaire au Moyen Age et sous la Renaissance. Paris: Gallimard, 1970.

BARTHES, R. Culture et tragédie. Essais sur la culture. Le Monde, Paris, p. 19, 4 abr. 1986. Disponivel em: http://www.analitica.com/bitblio/barthes/culture. asp. Acesso em: 20 out. 2019.

BAUDRILLARD, J. Simulacres et Simulation. Paris: Galilée, 1981.

BORGES, J. L. The Unending Gift. In: BORGES, J. L. Elogio da sombra. Lisboa: Teorema, 1998. p. 386. (Obras Completas, v. 2 - 1952-1972).

CARVALHO, C. A. Moisés de Lemos Martins lentrevista]. Matrizes, São Paulo, v. 13, n. 1, p. 93-106, 2019. Disponivel em: http://dx.doi.org/10.11606/issn.19828160.v13i1pg3-106.Acesso em: 28 out. 2019.

DERRIDA, J. La structure, le signe et le jeu dans le discours des sciences humaines. In: DERRIDA, J. L'écriture de la différence. Paris: Seuil, 1967. p. 409428. https://doi.org/10.1017/s0012217300030778

D'ORS, E. Du baroque. Paris: Gallimard, 1968.

DURAND, G. Les Structures anthropologiques de l'imaginaire. Paris: Bordas, 1969.
DURAND, G. L'imagination symbolique. Paris: Presses Universitaires de France, 1964

HEIDEGGER, M. La question de la technique. In: HEIDEGGER, M. Essais et conférences. Paris: Gallimard, 1988. p. 9-48).

HUGON, ST. Circumnavigations. L'imaginaire du voyage dans l'expérience Internet. Paris: CNRS Éditions, 2010

JENKINS, H. Transmedia Storytelling: Moving characters from books to films to video games canmake them stronger and more compelling. Technology Review, [S. l.], p. [1-3], 2003 Disponivel em: http://www. technologyreview.com/biomedicine/13052/page1/. Acesso em: 28 out. 2019.

JENKINS, H. Convergence Culture: Where old and new media collide. New York: New York University Press, 2006.

JOST, F. Novos comportamentos para antigas mídias ou antigos comportamentos para novas mídias? Matrizes, São Paulo, v. 4, n. 2, p. 93-109, 2011.

JÜNGER, E. La mobilisation totale, in L'Etat Universel: suivi de La mobilisation totale. Paris: Gallimard, 1990.

KERCKHOVE, D. de A Pele da Cultura: Uma investigação sobre a nova realidade electrónica. Lisboa: Relógio D'Água, 1997.

KITTLER, Fr. Técnicas artísticas. In: CRUZ, M. T., Novos Média. Novas Práticas. Lisboa: Vega, 2011. p. 10-19.

KUHN, Th. The Structure of Scientific Revolutions Chicago: University of Chicago Press, 1962.

LYOTARD, Fr. La Condition Post-moderne. Paris, Ed de Minuit, 1979

MAFFESOLI, M. Le temps des tribus. Le déclin de l'individualismes dans les sociétés de masse. Paris: Méridiens, Klincksieck, 1988. https://doi. org/10.2307/40183349

MAFFESOLI, M. Au creux des apparences. Pour une éthique de l'esthétique. Paris: La Table Ronde, 1990.

MAFFESOLI, M. L'instant éternnel. Le retour du tragique dans les sociétés postmodernes. Paris: Denoël, 2000.

MAFFESOLI, M.; MARTINS, M. À propos de l'imaginaire des médias. Sociétés, Paris, v. 111, p. 5-9, 2011. Disponivel em: http://hdl.handle.net/1822/23797. Acesso em: 30 out. 2019

MANOVICH, L. The language of new media. Cambridge, Massachusetts: MIT Press, 2001.

MARINETTI, F. T. Manifesti Futuristi. In Luciano De Maria (ed.). Tommaso Marinetti e il Futurismo, classici moderni, collezione Oscar, Mondadori spa Milano, 1973. Ed. original: Figaro, 20 de fevereiro de 1909. Disponivel em: http://www.classicitaliani.it/futuris$\mathrm{mo} / \mathrm{manifesti} / \mathrm{marinetti} f$ fondazione.htm. Acesso em: 10 out. 2015. https://doi.org/10.3726/b15151

MARTINS, M. L. A biblioteca de Babel e a árvore do conhecimento. O Escritor, 11/12, 235-240, 1998. Disponivel em: http://hdl.handle.net/1822/30068. Acesso em: 30 out. 2019. 
MARTINS, M. L. O trágico na modernidade, Interact, Braga, POR, n. 5, p. 1-10, 2002a. Disponivel em: http:// hdl.handle.net/1822/1087. Acesso em: 24 out. 2019

MARTINS, M. L. O trágico como imaginário da era mediática. Comunicação e Sociedade, Paris, v. 4. p. 73-79, 2002b. Disponivel em: http://hdl.handle. net/1822/25340. Acesso em: 24 out. 2019. https:// doi.org/10.17231/comsoc.4(2002).1265

MARTINS, M. L. De animais da promessa a animais em sofrimento de finalidade. O Escritor, Braga, POR, n. $18 / 20$, p. 351-354, 2002c. Disponivel em: http://hdl. handle.net/1822/1676. Acesso em: 28 out. 2019

MARTINS, M. L. O quotidiano e os média. Todas As Letras, São Paulo, v. 5, n. 5. p. 97-105, 2003. Disponível em: http://hdl.handle.net/1822/23792. Acesso em: 28 out. 2019

MARTINS, M. L. Espaço público e vida privada. Revista Filosófica de Coimbra, Coimbra, n. 27, p. 157-172, 2005. Disponivel em: http://hdl.handle. net/1822/23799. Acesso em: 30 set. 2019. https:// doi.org/10.17231/comsoc.12(2007).1092

MARTINS, M. L. Nota introdutória. A época e as suas ideias. Comunicação e Sociedade, Paris, v. 12, p. 5-7, 2007a. Disponivel em: http://hdl.handle. net/1822/24115. I.. Acesso em: 30 set. 2019.

MARTINS, M. L. La nouvelle érotique interactive. Sociétés, Paris, v. 96, n. 2, p. 21-27, 2007b. Disponivel em: http://hdl.handle.net/1822/23767. https://doi. org/10.3917/soc.096.0021. Acesso em: 15 set. 2019.

MARTINS, M. L. Da utopia da comunicação à comunicação sem utopia. Metamorfoses no sistema e nas relações de comunicação nos últimos trinta anos em Portugal. In: TORRES, A.; BAPTISTA, A. (org.). Sociedades Contemporâneas: Reflexividade e Acção. Porto: Afrontamento, 2008. p. 153-161. Disponivel em: http:// hdl.handle.net/1822/1082. Acesso em: 22 set. 2019. https://doi.org/10.15603/2175-7755/cs.v30n50p51-79

MARTINS, M. L. A mobilização infinita numa sociedade de meios sem fins. In: ÁLVARES, C; DAMÁSIO, M. (org.). Teorias e Práticas dos Media: Situando o Local no Global. Lisboa: Edições Lusófonas, 2010. p. 267-275. Disponivel em: http://hdl.handle. net/1822/24250. Acesso em: 26 set. 2019

MARTINS, M. L. Crise no castelo da cultura. Das estrelas para as telas. São Paulo: Annablume., 2011a. Disponivel em: em http://hdl.handle.net/1822/29167. Acesso em: 24 set. 2019

MARTINS, M. L. Médias et mélancolie: Le tragique, le baroque et le grotesque. Sociétés, Paris v. 111, p. 17-25, 2011b. Disponivel em: http://hdl. handle.net/1822/23866. https://doi.org/10.3917/ soc.111.0017. Acesso em: 8 set. 2019.

MARTINS, M. L. Technologie et rêve d'humanité Les Cahiers Européens de l'Imaginaire, [S. l.], v. 3. p. 56-61, 2011c. Disponivel em: http://hdl.handle. net/1822/24245 Acesso em: 8 set. 2019.
MARTINS, M. L. O que podem as imagens. Trajecto do uno ao múltiplo. In: MARTINS, M. L.; MIRANDA, J. B.; OLIVEIRA, M.; GODINHO, J. (ed.). Imagem e pensamento. Coimbra: Grácio Editor/CECS, 2011d. p. 129-135. Disponivel em: http://hdl.handle. net/1822/25345. Acesso em: 18 set. 2019.

MARTINS, M. L. Média digitais: hibridez, interactividade, multimodalidade. Revista de Comunicação e Linguagens, Lisboa, 43/44: 49-60, 2012. Disponivel em: http://hdl.handle.net/1822/25606. Acesso em: 27 out. 2019. https://doi.org/10.3917/soc.111.0017

MARTINS, M. L. O corpo morto: mitos, ritos, superstições. Revista Lusófona de Estudos Culturais, Braga, POR, v. 1, n. 1, p. 109-134, 2013. Disponivel em: http://hdl.handle.net/1822/29225. http://dx.doi. org/10.21814/rlec.11. Acesso em: 27 out. 2019.

MARTINS, M. L. Mélancolies de la mode. Le baroque, le grotesque et le tragique. Les Cahiers Européens de L'Imaginaire, [S. L.], v. 7. p. 114-119, 2015a. Disponivel em: http:// hdl.handle.net/1822/35333. Acesso em: 27 out. 2019.

MARTINS, M. L. Média digitais e lusofonia. In: M. L. Martins (ed.). Lusofonia e Multiculturalismo. Promessa e Travessia. Vila Nova de Famalicão: Húmus, 2015b. p. 27- 56. Disponivel em: http://hdl.handle. net/1822/39698. Acesso em: 20 out. 2019.

MARTINS, M. L. Declinações trágicas, barrocas e grotescas na moda contemporânea. In: MARTINS, M. L.; Correia, M. L.; Vaz, P. B.; Antunes, E. (ed.). Figurações da morte nos média e na cultura: entre o estranho e o familiar. Braga: CECS, 2016. p. 187-205 Disponivel em: http://hdl.handle.net/1822/43358. Acesso em: 18 out. 2019. https://doi.org/10.22533/ at.ed.7841924041

MARTINS, M. L. Comunicação da ciência, acesso aberto do conhecimento e repositórios digitais. $\mathrm{O}$ futuro das comunidades lusófonas e ibero-americanas de Ciências Sociais e Humanas. In: M. L. MARTINS (ed.). A internacionalização das comunidades lusófonas e ibero-americanas de Ciências Sociais e Humanas: O caso das Ciências da Comunicação. Vila Nova de Famalicão: Húmus/CECS, 2017. p. 19-58. Disponivel em: http://hdl.handle.net/1822/51039. Acesso em: 18 out. 2019. https://doi.org/10.17231/ comsoc.34(2018).2937

MARTINS, M. L. Os países lusófonos e o desafio de uma circum-navegação tecnológica. Comunicação e Sociedade, Braga, POR, 34: 87-101, 2018.. Disponivel em: http://hdl.handle.net/1822/57437. Acesso em: 18 set. 2019

MARTINS, M. L.; CORREIA, M. L. (org.). Do Post ao Postal. Famalicão, Húmus., 2014. Disponivel em: http://hdl.handle.net/1822/35295. Acesso em: 18 set. 2019. https://doi.org/10.3917/soc.111.0163

MARTINS, M. L., OLIVEIRA, M.; CORREIA, M. L. Les images numériques s'imaginent l'archaïque: mettre en perspective les cartes postales. Sociétés, Paris, v. 111, p. 163- 177, 2011. Disponivel em: http://hdl.handle.net/1822/23808. Acesso em: 18 set. 2019.

PERNIOLA, M. O Sex Appeal do Inorgânico. Ariadne: Lisboa, 2004. 
ROSA, J. G. O Grande Sertão: Veredas. Rio de Janeiro: Nova Fronteira, 2001

ROUSSET, J. La littérature de l'âge baroque en France: Circé et le Paon. Paris: Corti, 1953.

SALMON, Ch. Storytelling. La Machine à fabriquer des histories et à formater les esprits. Paris: La Découverte, 2007

SCOLARI, C. A. Transmedia Storytelling. Implicit consumers, narrative worlds, and branding in contemporary media production." International Journal of Communication, Los Angeles, CA. v. 3, p. 586-606, 2009.

SCOLARI, C. A. A construção de mundos possiveis se tornou um processo coletivo (entrevista). Matrizes,

São Paulo, v.4, n. 2, p. 127-136, 2011.

SCOLARI, C. A. Narrativas Transmedia: Cuando todos los medios cuentan. Barcelona: Deusto, 2013. https:// doi.org/10.26422/aucom.2013.0202.alba

SLOTERDIJK, P. La mobilisation infinie. Paris: Christian Bourgois Ed., 2000.

SODRÉ, M.; PAIVA, R. O império do grotesco. Rio de Janeiro: Ed. Mauad, 2002.

SOUSA, M. N. A Propagação de histórias através de múltiplos média: por um modelo conceptual de transmediação, adaptação e outros exercicios derivativos. 2018. 567 f. Tese (Doutoramento em Ciências da Comunicação da Comunicação) - Universidade do Minho, Braga, Portugal, 2018. Disponivel em: http://hdl.handle.net/1822/56395. Acesso em: 8 set. 2019. https://doi.org/10.18225/9788570131485.cap13

SOUSA, M. N.; ZAGALO, N.; MARTINS, M. L. "'Eu também posso propagar histórias'. A adaptação e as narrativas transmediáticas na era da participação". Comunicação e Sociedade, Braga, POR, v. 22, p. 167-183, 2012. Disponivel em: http://revistacomsoc. $\mathrm{pt} / \mathrm{index}$.php/comsoc/article/view/1280. Acesso em: 30 out. 2019. https://doi.org/10.17231/comsoc.22(2012).1280

SOUSA, M. N.; Martins, M. L.; ZAGALO, N. Transmedia storytelling: The roles and stakes of the different participants in the process of a convergent story, in divergent media and artefacts. In: LUGMAYR, A.; DAL Zotto, C. (ed.). Media convergence handbook. Berlin/ Heidelberg: Springer-Verlag, 2016. v. 2, p. 117-135. https://doi.org/10.1007/978-3-642-54487-3_7

STEINER, G. No Castelo do Barba Azul. Notas para a redefinição da cultura. Lisboa: Relógio d'Água, 1992.

VIRILIO, P. Entretien avec Paul Virilio. Le Monde del'Education, [S. l.], v. 294, n. 135-138, juil./août. 2001

WASKO, J. Hollywood in the Information Age. Oxford: Polity Press, 1994

WÖLFFLIN, H. Renacimiento y barroco. Barcelona: Paidós, 1991

ZAGALO, N.; BRANCO, P. Nota introdutória. A nova revolução criativa. Comunicação e Sociedade, Braga, POR, v. 12, n. 2, p. 5-6, 2012. Acesso em: 18 set. 2019 http://dx.doi.org/10.17231/comsoc.22(2012).1270.

\section{Endereço:}

Moisés de Lemos Martins

Universidade do Minho, Campus de Gualtar, 4710-057. Braga, Portugal 